Article

\title{
Immune-Related Functional Differential Gene Expression in Koi Carp (Cyprinus carpio) after Challenge with Aeromonas sobria
}

\author{
Omkar Byadgi ${ }^{1}{ }^{(D)}$, Yao-Chung Chen ${ }^{1}$, Shun Maekawa ${ }^{1}$, Pei-Chyi Wang ${ }^{1,3, *}$ and \\ Shih-Chu Chen 1,2,3,4,* (D) \\ 1 Department of Veterinary Medicine, College of Veterinary Medicine, \\ National Pingtung University of Science and Technology, Pingtung 91201, Taiwan; \\ omkarcof1@gmail.com (O.B.); r02632007@gmail.com (Y.-C.C.); shun84topaz04@gmail.com (S.M.) \\ 2 International Degree Program of Ornamental Fish Science and Technology, International College, \\ National Pingtung University of Science and Technology, No. 1, Shuefu Road, Neipu, \\ Pingtung 91201, Taiwan \\ 3 Southern Taiwan Fish Disease Center, National Pingtung University of Science and Technology, No. 1, \\ Shuefu Road, Neipu, Pingtung 91201, Taiwan \\ 4 Research Center for Animal Biologics, National Pingtung University of Science and Technology, \\ Pingtung, No. 1, Shuefu Road, Neipu, Pingtung 91201, Taiwan \\ * Correspondence: pc921003@gmail.com (P.-C.W.); scchen@mail.npust.edu.tw (S.-C.C.); \\ Tel.: +886-8-770-3202 (ext. 5076) (P.-C.W. \& S.-C.C.); Fax: +886-8-774-0571 (P.-C.W. \& S.-C.C.)
}

Received: 21 May 2018; Accepted: 16 July 2018; Published: 20 July 2018

Abstract: In order to understand the molecular basis underlying the host immune response of koi carp (Cyprinus carpio), Illumina HiSeq ${ }^{\mathrm{TM}} 2000$ is used to analyze the muscle and spleen transcriptome of koi carp infected with Aeromonas sobria (A. sobria). De novo assembly of paired-end reads yielded 69,480 unigenes, of which the total length, average length, N50, and GC content are 70,120,028 bp, $1037 \mathrm{bp}, 1793 \mathrm{bp}$, and $45.77 \%$, respectively. Annotation is performed by comparison against various databases, yielding 42,229 (non-redundant protein sequence (NR): 60.78\%), 59,255 (non-redundant nucleotide (NT): 85.28\%), 35,900 (Swiss-Prot: 51.67\%), 11,772 (clusters of orthologous groups (COG): 16.94\%), 33,057 (Kyoto Encyclopedia of Genes and Genomes (KEGG): 47.58\%), 18,764 (Gene Ontology (GO): $27.01 \%$ ), and 32,085 (Interpro: $46.18 \%$ ) unigenes. Comparative analysis of the expression profiles between bacterial challenge fish and control fish identifies 7749 differentially expressed genes (DEGs) from the muscle and 7846 DEGs from the spleen. These DEGs are further categorized with KEGG. Enrichment analysis of the DEGs and unigenes reveals major immune-related functions, including up-regulation of genes related with Toll-like receptor signaling, complement and coagulation cascades, and antigen processing and presentation. The results from RNA-Seq data are also validated and confirmed the consistency of the expression levels of seven immune-related genes after $24 \mathrm{~h}$ post infection with qPCR. Microsatellites $(11,534)$, including di-to hexa nucleotide repeat motifs, are also identified. Altogether, this work provides valuable insights into the underlying immune mechanisms elicited during bacterial infection in koi carp that may aid in the future development of disease control measures in protection against $A$. sobria.

Keywords: Illumina paired-end sequencing; immune response; koi carp (Cyprinus carpio); Aeromonas sobria; transcriptome

\section{Introduction}

Aeromonas (Aeromonadaceae) species are ubiquitous and can cause infections not only in humans but also in fish. Aeromonas are isolated from various sources, such as fresh, estuarine, or surface waters, 
sewage, food products, healthy or diseased fish, or animal and human feces and are ubiquitous in aquatic ecosystems [1-5]. Aeromonas diseases in fish are mainly caused by the release of two important virulence factors, namely extracellular hemolysin and aerolysin [6-8]. At ambient temperature, Aeromonas species are known as active spoilers of fish and meat $[9,10]$. They are opportunistic pathogens of fish and can cause outbreak during stress conditions, such as poor water quality, overcrowding, and rough handling [1,11,12].

Aeromonas spp. are gram-negative, straight, nonspore-forming rods, generally cytochrome oxidase positive, facultatively anaerobic, and chemoorganotrophic and are characterized by their ability to grow in $0 \% \mathrm{NaCl}$ but not in $6 \% \mathrm{NaCl}$ [1]. Aeromonas septicemia causes fatal infectious disease in cold-blooded animals [13]; in humans [14-16], disease is often caused by the motile Aeromonas, particularly Aeromonas hydrophila, Aeromonas sobria (A. sobria), and Aeromonas caviae.

In this study, we concentrated on A. sobria, which causes septicaemia in cultured marine and freshwater fish in Taiwan. A. sobria infections frequently result in considerable economic loss to fish farmers in Taiwan. There are several studies of transcriptome profile in fish upon exposure to different pathogens, such as Aeromonas hydrophila infection in zebrafish (Danio rerio), grass carp (Ctenopharyngodon idella), darkbarbel cat fish (Pelteobagrus vachellii) [17-19] and Vibrio anguillarum infection in soles (Cynoglossus semilaevis) [20], indicating the activation of specific immune pathways after bacterial infection. Other examples include orange-spotted grouper (Epinephelus coioides) [21], the blunt snout bream (Megalobrama amblycephala) [22], the Chilean abalone Concholepas (Gastropoda, Muricidae) [23], grass carp (Ctenopharyngodon idella) [24], blowfish or fugu (Takifugu rubripes) [25], large yellow croaker (Larimichthys crocea) [26], and Nile tilapia (Oreochromis niloticus) [27,28], demonstrating that the pathways and immune gene expression are dependent on individual host and pathogen. In addition, other studies reported on response to immune stimuli, pathogenic infection, or environmental stress [29-31]. However, to the best of our knowledge, there is no information available on the differential gene expression profile for the entire fish transcriptome in response to A. sobria challenge and infection in koi carp.

\section{Results}

\subsection{Transcriptome Sequence Assembly and Functional Annotation}

Of 69,480 unigenes, 60,593 (87.21\%) were annotated using at least one database, including 42,229 (NR: 60.78\%), 59,255 (NT: 85.28\%), 35,900 (Swiss-Prot: 51.67\%), 11,772 (COG: 16.94\%), 33,057 (KEGG: 47.58\%), 18,764 (GO: 27.01\%), and 32,085 (Interpro: 46.18\%) unigenes. (Supplementary Materials, Table S1a,b). In total, 26,870 (63.08\%) COG-annotated putative proteins were classified into 25 categories (Supplementary Materials, Figure S1). The largest functional cluster was determined to be 'replication recombination and modification' (2486), followed by 'transcription' (2359) and 'translation, ribosomal structure, and biogenesis' (1949).

\subsection{Number of Differentially Expressed Genes after Aeromonas Sobria Challenge}

Comparison of gene expression levels between the fish, subjected to bacterial challenge and control fish, identified a total of 7749 differentially expressed genes (DEGs) in the muscle and 7846 in the spleen $(p<0.05)$. This included 6300 up-regulated and 1449 down-regulated genes in the muscle, and 5111 up-regulated and 2735 down-regulated genes in the spleen, revealing a total of 7192 and 7280 (Figure 1). The DEGs in the muscle and spleen were mainly annotated into the following categories: 'biological process', 'cellular component', and 'molecular function' (Figures 2 and 3). The most annotated unigenes belonged to the following categories: cellular process, single-organism process and metabolic process (from the 'biological process' category); cell, cell part and organelle (from the 'cellular component' category); and binding, catalytic activity and molecular transducer activity (from the 'molecular function' category). 


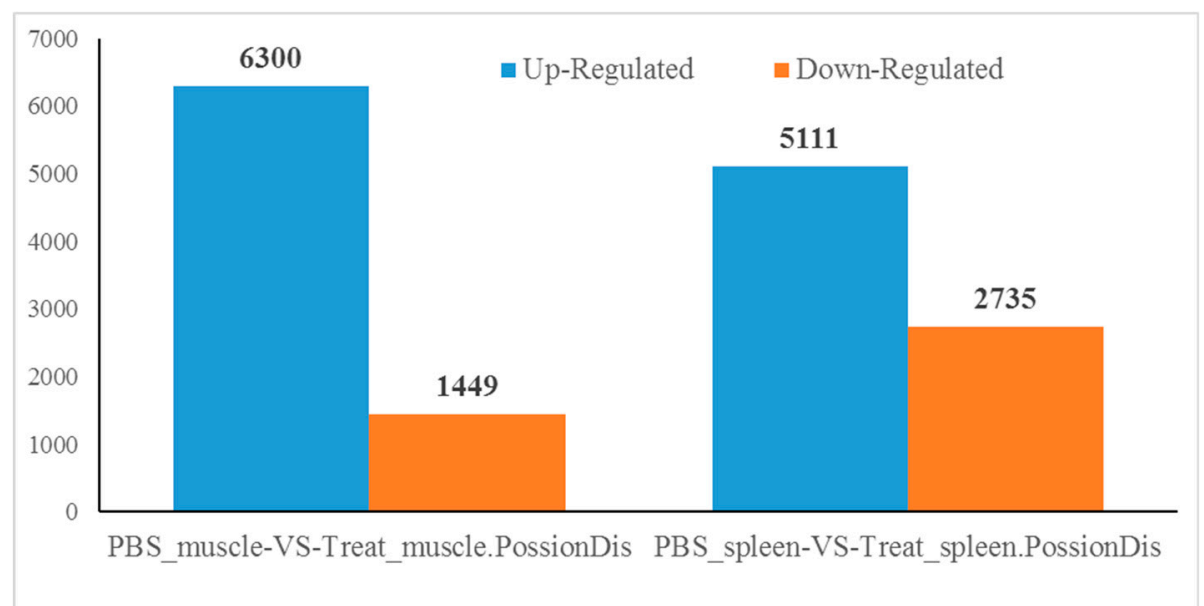

Figure 1. Up-regulation and down-regulation of differential expressed genes (DEGs) in muscle and spleen after challenge with Aeromonas sobria (A. sobria) in koi carp.

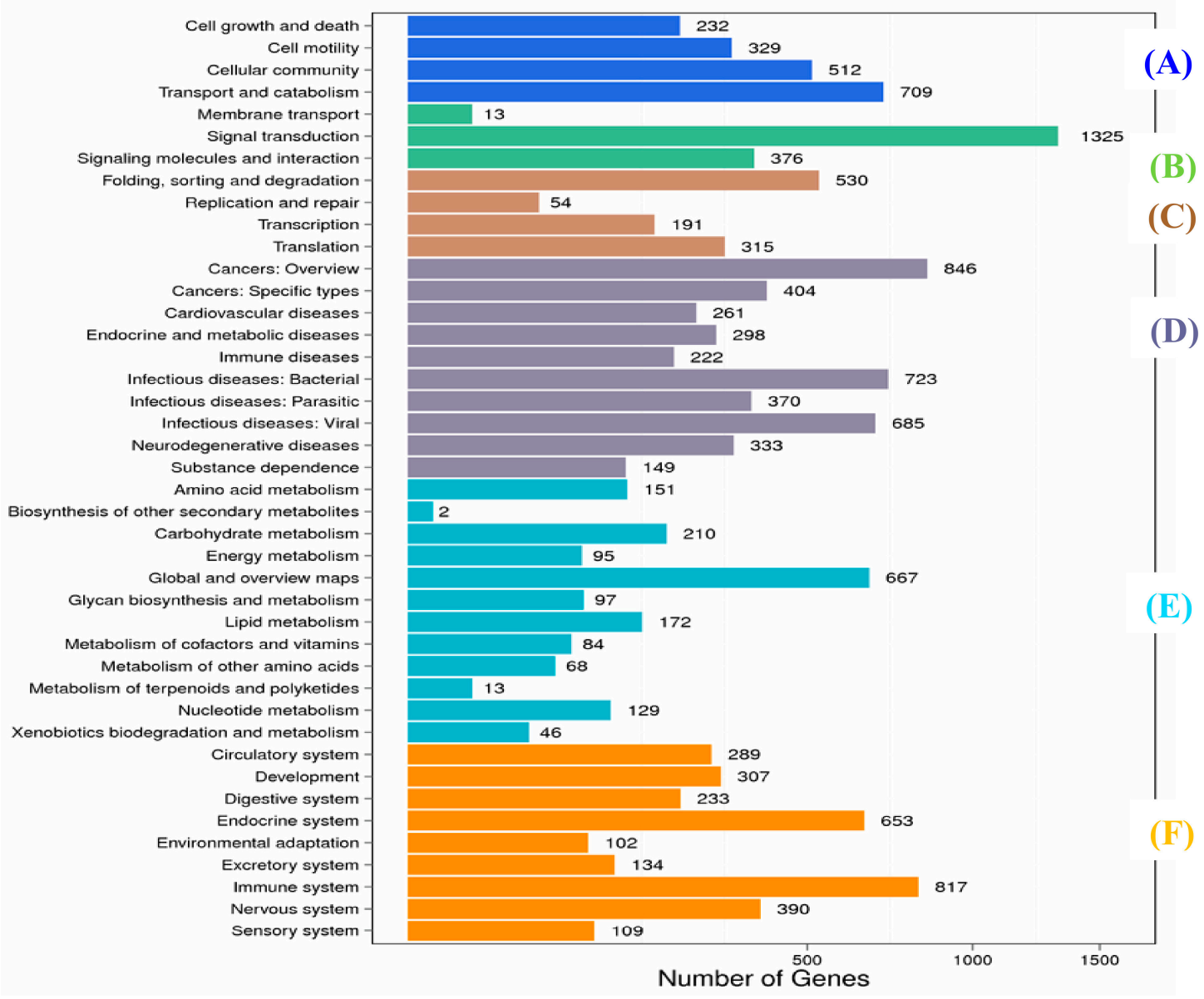

Figure 2. KEGG (Kyoto Encyclopedia of Genes and Genomes) classifications of DEGs (differentially expressed genes) in muscle. (A) Cellular processes; (B) environmental information processing organismal systems; (C) genetic information processing metabolism; (D) human diseases; (E) metabolism and (F) organismal systems. 


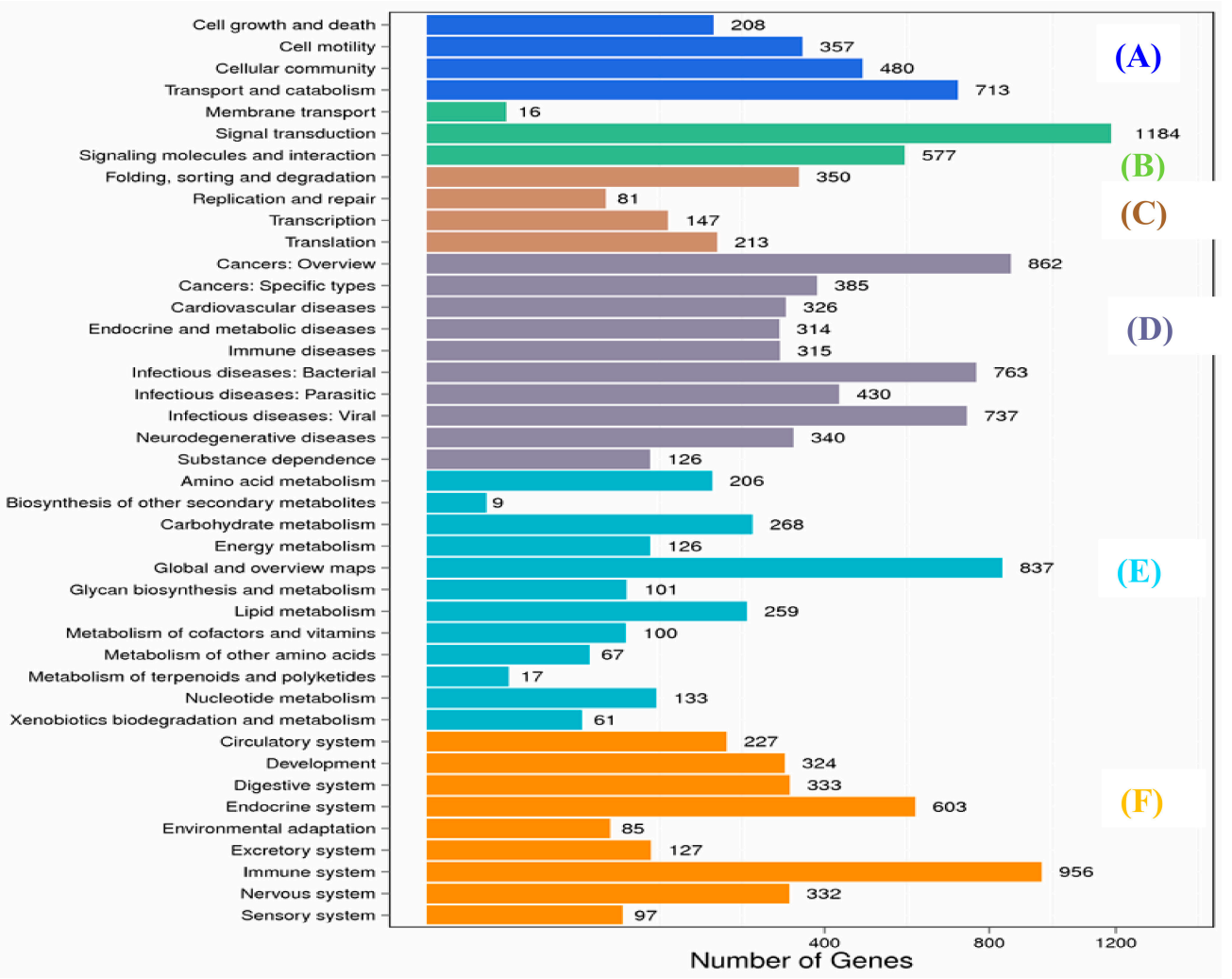

Figure 3. KEGG (Kyoto Encyclopedia of Genes and Genomes) classifications of DEGs (differentially expressed genes) in spleen. (A) Cellular processes; (B) environmental information processing organismal systems; (C) genetic information processing metabolism; (D) human diseases; (E) metabolism and (F) organismal systems.

Overall, from DEGs in muscle and spleen, KEGG analysis annotated the genes into 286 pathways, which were classified into 6 main categories (Figures 2 and 3), namely cellular processes, environmental information processing organismal systems, genetic information processing metabolism, human diseases, metabolism, and organismal systems.

A total of 1325 DEGs in the muscle were annotated into signal transduction pathway terms with 26 sub-pathways (Supplementary Materials, Table S2a), including the PI3K Akt signaling pathway (317 genes), Rap1 signaling pathway (242 genes), MAPK signaling pathway (218 genes), Ras signaling pathway (199 genes), TNF signaling pathway (169 genes), cGMP-PKG signaling pathway (172 genes), JAK-Stat signaling pathway (142 genes), and cAMP signaling pathway (154 genes).

A total of 1184 DEGs in the spleen were annotated into 26 sub-pathways (Supplementary Materials, Table S2b), including the Rap1 signaling pathway (327 genes), PI3K Akt signaling pathway (326 genes), MAPK signaling pathway (174 genes), Ras signaling pathway (170 genes), TNF signaling pathway (145 genes), Phospholipase D signaling pathway (146 genes), Hippo signaling pathway (145 genes), phosphatidylinositol signaling pathway (146 genes), cAMP signaling pathway (136 genes), and NF-K B signaling pathway (132 genes).

The DEGs of the immune system were annotated in 16 sub-categories in the spleen (S T3b), including leukocyte transendothelial migration (267 genes), platelet activation (239 genes), hematopoietic cell lineage (205 genes), T cell receptor signaling pathway (143 genes), natural killer cell-mediated cytotoxicity (171 genes), NOD-like receptor signaling pathway (80 genes), chemokine signaling pathway (164 genes), intestinal immune network for IgA production (86 genes), Fc gamma R-mediated phagocytosis (107 genes), B cell receptor signaling pathway (87 genes), antigen processing and presentation (99 genes), Toll-like receptor signaling pathway (Figure 4) (85 genes), Fc epsilon 
RI signaling pathway (56 genes), cytosolic DNA-sensing pathway (30 genes) and RIG-I-like receptor signaling pathway (43 genes), complement and coagulation cascades (Figure 5) (163 genes).

The immune system showed the highest number of DEGs in the muscle (817 genes); these were divided into 16 sub-categories (Supplementary Materials, Table S3a,b), including leukocyte transendothelial migration (203 genes), platelet activation (184 genes), hematopoietic cell lineage (127 genes), T cell receptor signaling pathway (147 genes), natural killer cell-mediated cytotoxicity (119 genes), NOD-like receptor signaling pathway (98 genes), Fc gamma R-mediated phagocytosis (145 genes), B cell receptor signaling pathway (107 genes), intestinal immune network for IgA production (55 genes), antigen processing and presentation (75 genes), Toll-like receptor signaling pathway (Figure 6) (114 genes), complement and coagulation cascades (Figure 7) (43 genes), Fc epsilon RI signaling pathway (76 genes), cytosolic DNA-sensing pathway (36 genes), and RIG-I-like receptor signaling pathway (65 genes).

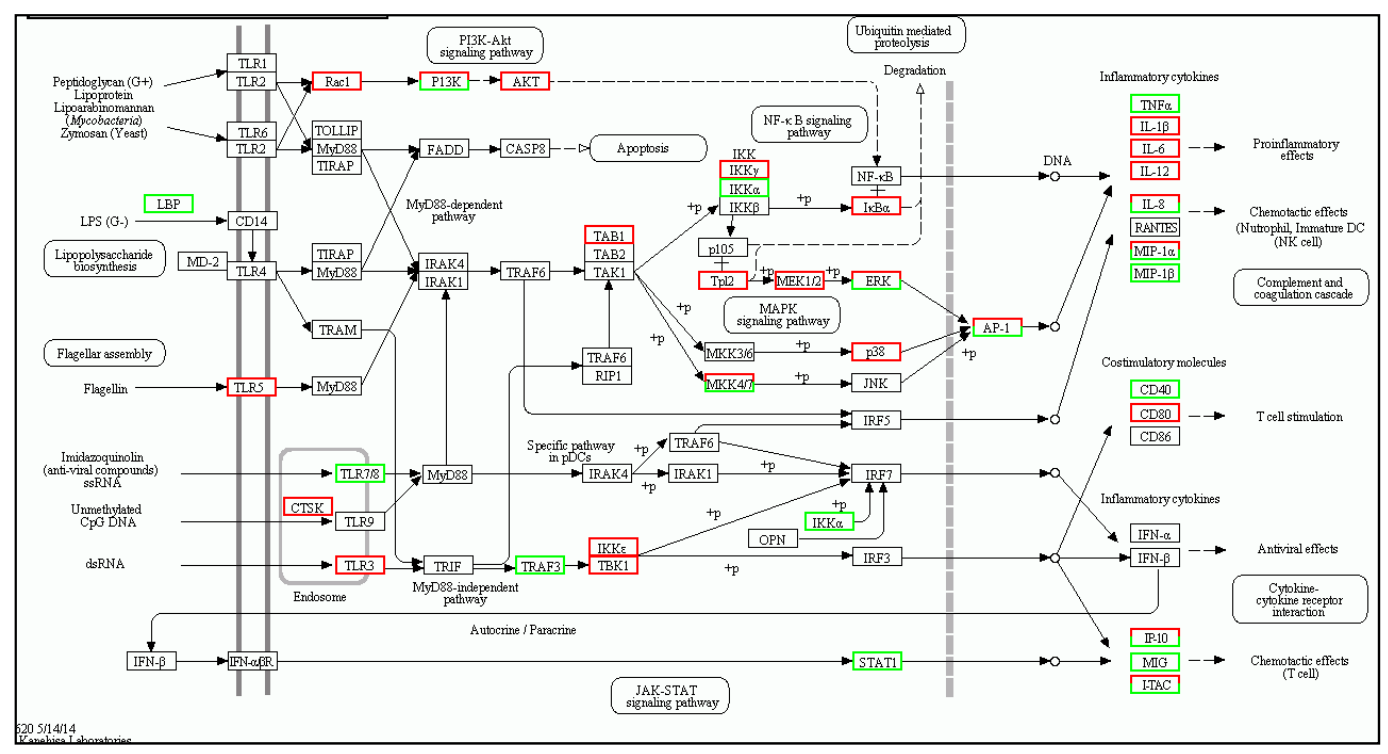

Figure 4. Toll-like receptor signaling mapping in spleen by KEGG. Red boxes indicate significantly differentially up-regulated expression and white boxes indicate unchanged expression in the transcriptomic profile.

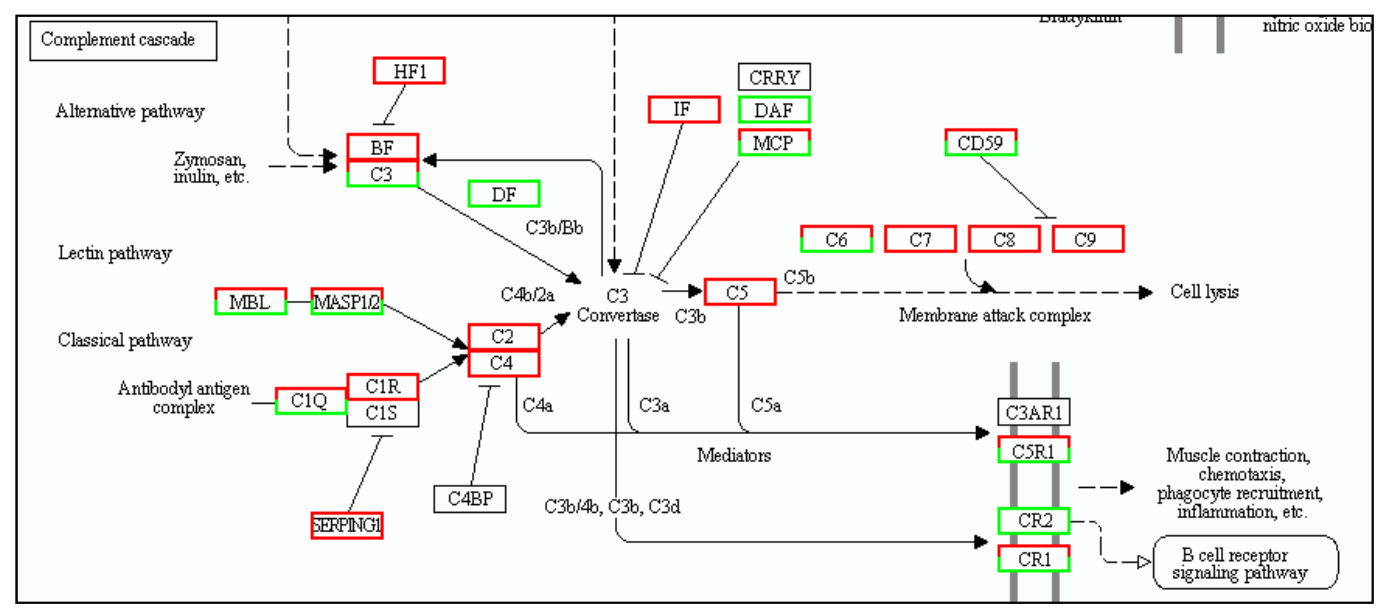

Figure 5. Complement cascade pathway mapping in spleen by KEGG. Red boxes indicate significantly differentially up-regulated expression, green box indicate down-regulated expression and white boxes indicate unchanged expression in the transcriptomic profile. 


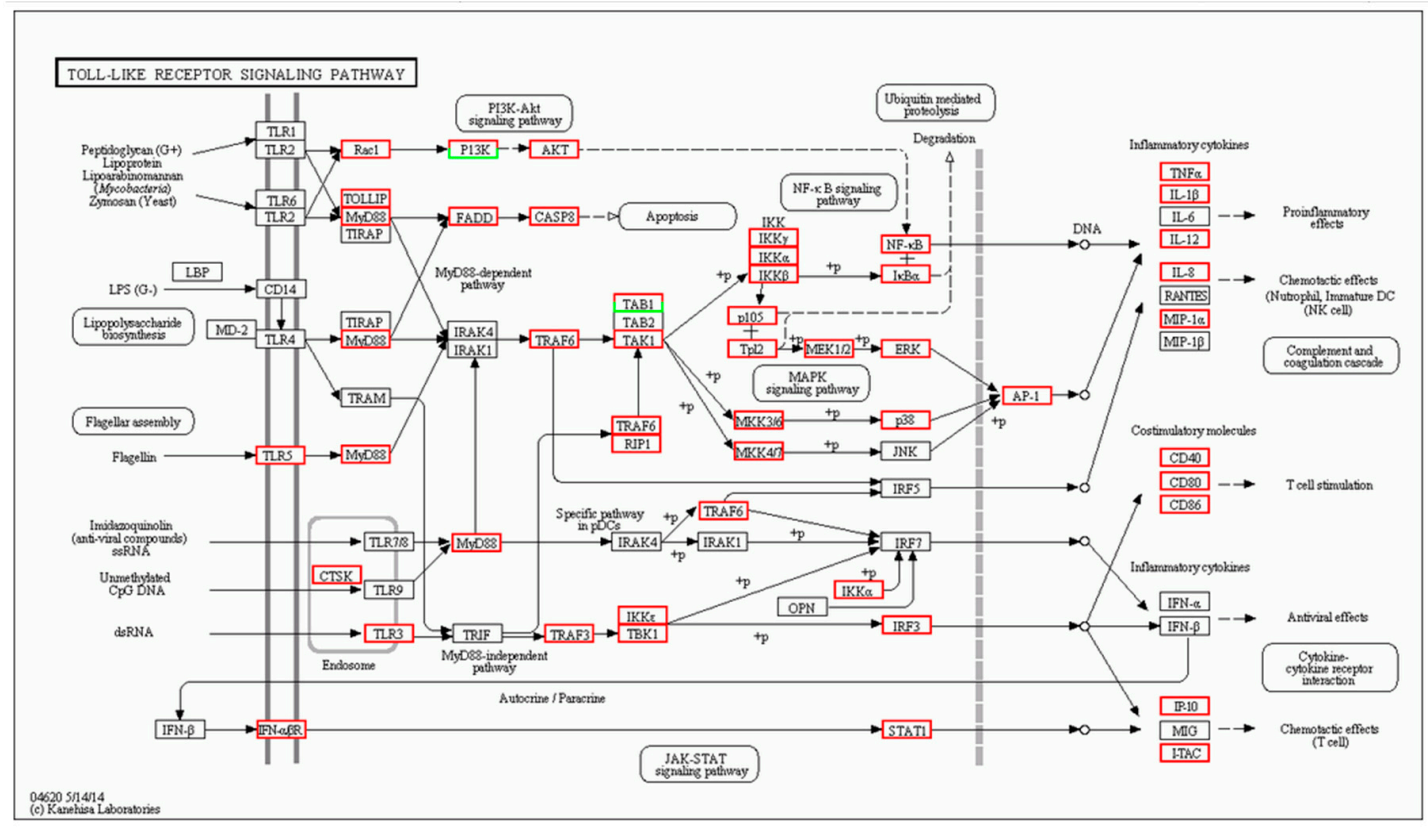

Figure 6. Toll-like receptor signaling mapping in muscle by KEGG. Red boxes indicate significantly differentially up-regulated expression and white boxes indicate unchanged expression in the transcriptomic profile.

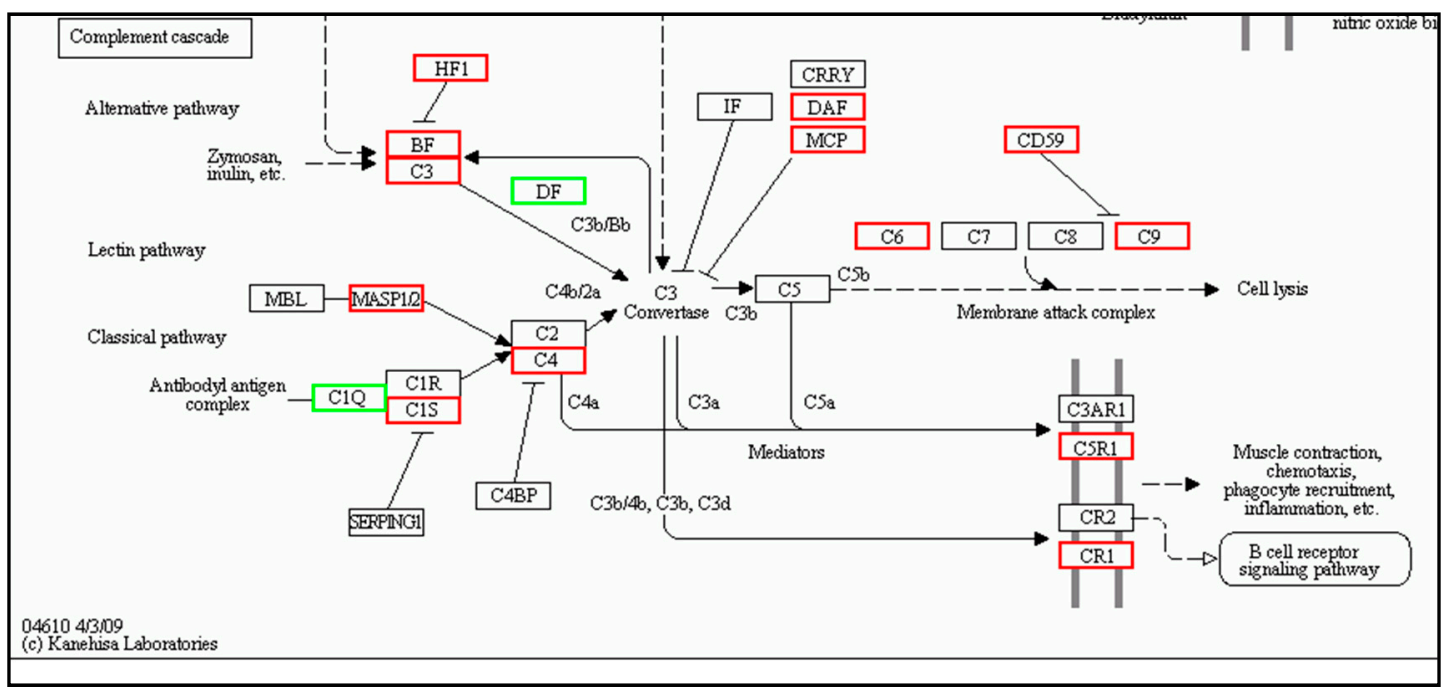

Figure 7. Complement cascade pathway mapping in muscle by KEGG. Red boxes indicate significantly differentially up-regulated expression, green box indicate down-regulated expression and white boxes indicate unchanged expression in the transcriptomic profile.

DEGs with an absolute value of fold change $>1$ were selected from the immune-related category from the muscle and spleen and are presented in Table 1. Although most of the selected genes could be found in other categories, the genes were related to the complement system, antigen processing and presentation, and the Toll-like receptor signaling pathway. 
Table 1. Immune-related DEGs regulated after infection in muscle and spleen of koi carp.

\begin{tabular}{|c|c|c|c|c|c|}
\hline Gene & $\begin{array}{c}\text { log2 Fold Change } \\
\text { (Treat_muscle/PBS_muscle) }\end{array}$ & $\begin{array}{c}\text { Up/Down-Regulation } \\
\text { (Treat_muscle/PBS_muscle) }\end{array}$ & Gene & $\begin{array}{c}\log 2 \text { Fold Change } \\
\text { (Treat_spleen/PBS_spleen) }\end{array}$ & $\begin{array}{c}\text { Up/Down-Regulation } \\
\text { (Treat_spleen/PBS_spleen) }\end{array}$ \\
\hline \multicolumn{3}{|c|}{ Innate Immunity } & \multicolumn{3}{|c|}{ Innate Immunity } \\
\hline tlr 5 & 4.360256 & Up & tlr 5 & 3.787257 & Up \\
\hline myd 88 & 2.619664 & Up & myd88 & 3.701566 & Up \\
\hline traf6 & 1.726865 & Up & tlr7 & -3.67177 & Down \\
\hline tak1 & 4.95002 & Up & $t b k 1$ & 1.701046 & Up \\
\hline$t b k 1$ & 2.392317 & Up & tab1 & 3.308268 & Up \\
\hline$n f k b$ & 2.415037 & Up & stat1 & -1.15676 & Down \\
\hline $\operatorname{tnf}-\alpha$ & 9.337622 & Up & $\operatorname{tnf}$ & -9.17742 & Down \\
\hline$i l-1 \beta$ & 11.21396 & Up & $i l-1 \beta$ & 6.588696 & Up \\
\hline$i l-12$ & 2.374396 & Up & $i l-12$ & 2.670009 & Up \\
\hline$i l-8$ & 13.58918 & Up & $i l-8$ & 12.19013 & $\mathrm{Up}$ \\
\hline$c d 40$ & 8.438792 & Up & $c d 40$ & -1.38904 & Down \\
\hline \multicolumn{3}{|c|}{ Antigen Processing } & \multicolumn{3}{|c|}{ Antigen Processing } \\
\hline$t c r$ & 2.235073 & Up & $t c r$ & -4.78398 & Down \\
\hline$m h c-i$ & 7.857981 & Up & $m h c-i$ & 11.54978 & Up \\
\hline$m h c-i i$ & 3.933396 & Up & $m h c-i i$ & 1.144123 & Up \\
\hline$c d 8$ & 7.857981 & Up & $c d 8$ & 11.54978 & Up \\
\hline$c d 4$ & 3.933396 & Up & $c d 4$ & 1.144123 & Up \\
\hline hsp 70 & 4.422052 & Up & $h s p 70$ & 2.483444 & Up \\
\hline \multicolumn{3}{|c|}{ Complement Cascade } & \multicolumn{3}{|c|}{ Complement Cascade } \\
\hline$c 3$ & 6.954196 & Up & $c 3$ & 6.722808 & Up \\
\hline$c 4$ & 1.81526 & Up & $c 4$ & 2.656724 & Up \\
\hline $\begin{array}{l}\text { mannan-binding lectin } \\
\text { serine protease } 1\end{array}$ & 1.599362 & Up & $\begin{array}{l}\text { mannan-binding lectin } \\
\text { serine protease } 1\end{array}$ & 4.143954 & $\mathrm{Up}$ \\
\hline$c 6$ & 4.712957 & Up & $c 6$ & 1.467602 & Up \\
\hline alpha-2-macroglobulin & 5.612605 & Up & alpha-2-macroglobulin & 11.84314 & $\mathrm{Up}$ \\
\hline
\end{tabular}




\subsection{Simple Sequence Repeat and Single Nucleotide Polymorphism Discovery}

Among 47,881 unigene, 11,534 SSRs (Simple sequence repeat) were identified. The most abundant type of repeat motif was dinucleotide $(44.39 \%)$, followed by trinucleotide $(21.56 \%)$, quadra-nucleotide $(2.05 \%)$, penta-nucleotide $(0.6 \%)$, and hexa-nucleotide $(0.6 \%)$ repeats (Table 2$)$. The highest tandem repeat number was six, constituting $17.26 \%$ (Table 3 ).

Table 2. Simple sequence repeat (SSR) marker discovery.

\begin{tabular}{cc}
\hline Parameter & Number \\
\hline Total number of sequences examined: & 47,881 \\
Total size of examined sequences (bp): & $49,734,288$ \\
Total number of identified SSRs: & 11,534 \\
Number of SSRs containing sequences: & 8638 \\
Number of sequences containing more than 1 SSR: & 2103 \\
Number of SSRs present in compound formation: & 943 \\
\hline
\end{tabular}

Table 3. Number of Single nucleotide polymorphism detection with the repeat number.

\begin{tabular}{|c|c|c|c|c|c|c|c|c|}
\hline \multirow{2}{*}{$\begin{array}{l}\text { Repeat } \\
\text { Number }\end{array}$} & \multicolumn{6}{|c|}{ Motif Length } & \multirow{2}{*}{ Total } & \multirow{2}{*}{$\%$} \\
\hline & Mono- & Di- & Tri- & Quad- & Penta- & Hexa- & & \\
\hline 4 & 0 & 0 & 0 & 0 & 58 & 52 & 110 & 0.9 \\
\hline 5 & 0 & 0 & 1214 & 112 & 5 & 5 & 1336 & 11.58 \\
\hline 6 & 0 & 1358 & 542 & 78 & 5 & 8 & 1991 & 17.26 \\
\hline 7 & 0 & 705 & 324 & 14 & 1 & 2 & 1046 & 9.06 \\
\hline 8 & 0 & 496 & 242 & 13 & 0 & 0 & 751 & 6.51 \\
\hline 9 & 0 & 345 & 31 & 7 & 0 & 1 & 384 & 3.32 \\
\hline 10 & 0 & 292 & 34 & 3 & 0 & 2 & 331 & 2.86 \\
\hline 11 & 0 & 373 & 33 & 1 & 0 & 0 & 407 & 3.52 \\
\hline 12 & 802 & 279 & 27 & 1 & 1 & 0 & 1110 & 9.62 \\
\hline 13 & 575 & 69 & 15 & 2 & 0 & 0 & 661 & 5.73 \\
\hline 14 & 385 & 87 & 6 & 0 & 0 & 0 & 478 & 4.14 \\
\hline 15 & 239 & 104 & 6 & 2 & 0 & 0 & 351 & 3.04 \\
\hline$>15$ & 1787 & 1117 & 19 & 6 & 0 & 0 & 2929 & 25.39 \\
\hline Total & 3549 & 5121 & 2487 & 237 & 70 & 70 & 11,534 & 100 \\
\hline$\%$ & 30.76 & 44.39 & 21.56 & 2.05 & 0.6 & 0.6 & 99.96 & \\
\hline
\end{tabular}

A total of 21,098 candidate SNPs were identified, transitions $(13,161,62.38 \%)$ were the most common type, and SNPs were typically located at the first and third codon positions (Figure 8).

\subsection{RT-qPCR Analysis of Immune Related Genes Following Aeromonas sorbia Infection}

To validate the DEGs identified by RNA-Seq analysis, we performed RT-qPCR. Seven genes (C3, IL1 $\beta, I L 8, M y D 88, N F-\kappa B, T L R 5, T N F \alpha$ ) associated with the complement system, antigen processing, and toll-like receptors were detected in the spleen and muscle by RT-qPCR (Table 4). In the spleen of the infected fish, at $1 \mathrm{dpi}$, the expression levels of $I L 1 \beta, I L 8$, and MyD88 were significantly up-regulated. In the muscle at $1 \mathrm{dpi}$, the expression levels of $C 3, I L 1 \beta$, and $I L-8$ showed an upward trend, but these was not significant. 


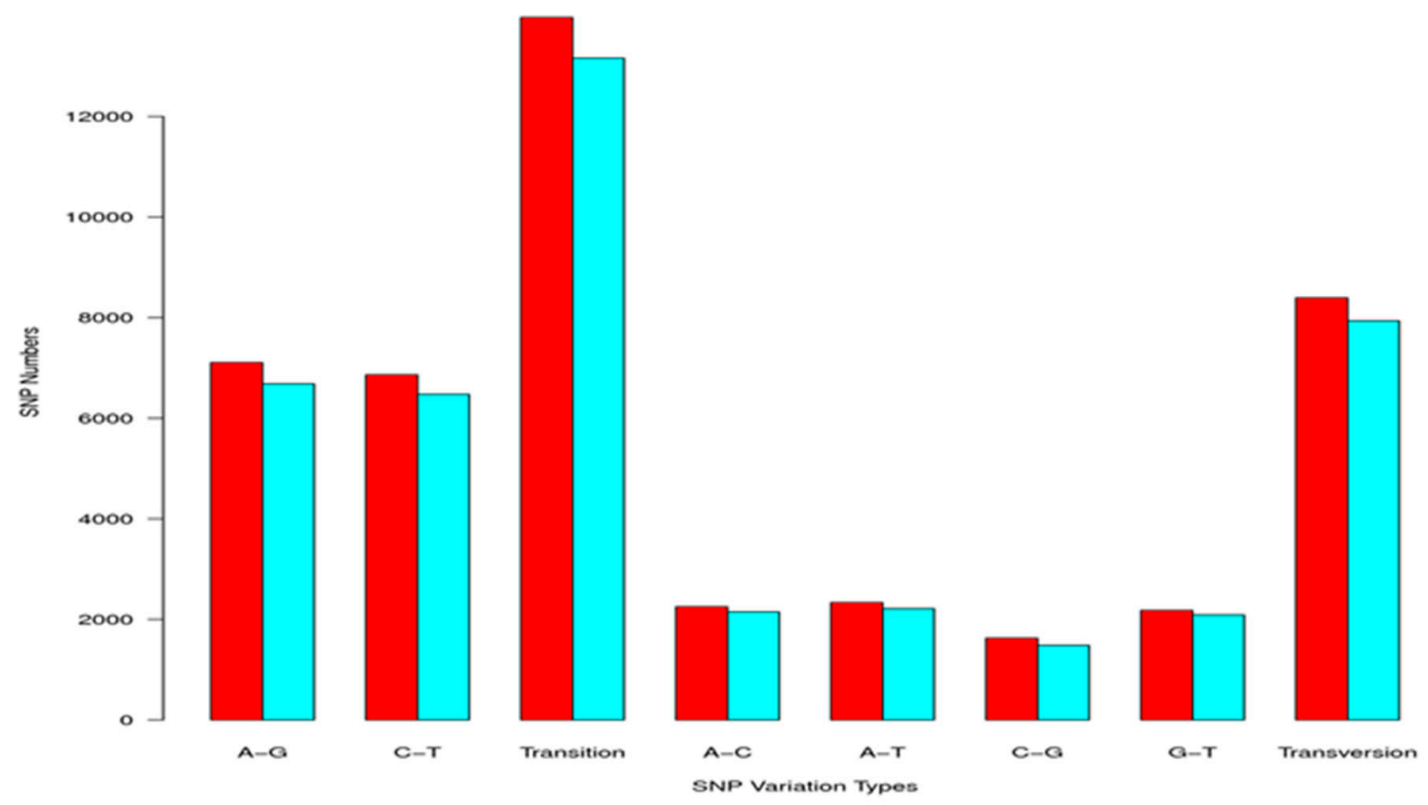

Figure 8. Statistics of Single nucleotide polymorphism (SNP) type in cDNA library from control and bacterial infection.

Table 4. Validation of relative expression levels of immune-related genes after A. sorbia infection from RNA-Seq and real-time polymerase chain reaction.

\begin{tabular}{ccccc}
\hline \multirow{2}{*}{ Gene } & \multicolumn{2}{c}{ Spleen } & \multicolumn{2}{c}{ Muscle } \\
\cline { 2 - 5 } & RNA-Seq & qPCR & RNA-Seq & qPCR \\
\hline C3 & 6.722808 & $2.99 \pm 1.90$ & 6.954196 & $2.68 \pm 1.84$ \\
IL-1 $\beta$ & 6.588696 & $* 24.73 \pm 5.75$ & 11.21396 & $1.23 \pm 0.45$ \\
$I L-8$ & 12.19013 & $* 140.77 \pm 77.4$ & 13.58918 & $5.79 \pm 3.82$ \\
MyD88 & 3.701566 & $2.92 \pm 0.85$ & 2.619664 & $0.76 \pm 0.24$ \\
NF- $\kappa b$ & -1.15676 & $1.50 \pm 0.58$ & 2.415037 & $0.56 \pm 0.16$ \\
TLR5 & 3.787257 & $9.14 \pm 4.53$ & 4.360256 & $1.08 \pm 0.69$ \\
TNF $\alpha$ & -9.17742 & $5.33 \pm 2.89$ & 9.337622 & $0.25 \pm 0.03$ \\
\hline
\end{tabular}

* Key gene molecules showing difference in expression level between RNA-seq and qPCR in spleen.

\section{Discussion}

This study used the spleen and muscle of koi carp at $24 \mathrm{~h}$ after infection with $A$. sobria as experimental samples to determine immune-related genes and signaling pathways activated during the early stage of infection. As expected, the results showed that many immune-related genes in the koi carp were up-regulated significantly after A. sobria infection. The most significantly up-regulated genes associated with immunity were the pro-inflammatory cytokine-related and the signal transduction related genes, such as IL-1 $\beta$, TNF receptor, CXC chemokine, TGF- $\beta, N F-\kappa B$, and some other immune-related genes; pathogen recognition related genes were also significantly up-regulated.

After assembly, 69,480 unigenes were generated, with an average length of $578 \mathrm{bp}$, which was longer than those achieved in previous studies, using the Roche GS FLX 454 system with MIRA assembler (a length range of 118-2065 bp and an average length of $495 \mathrm{bp}$ ) [32] or Illumina/Hiseq-2000 with the assembling program-SOAP (a length range of 200-5245 bp and an average length of $412 \mathrm{bp}$ ) [33]. This difference in sequence quality is possibly owing to the difference in sampling tissue and the different de novo assemblers. Trinity assemblies, which were used in this study, have a consistently better performance than the other tools used in transcriptome assembling, even in the absence of a reference genome [34,35]. In contrast to Trinity, the SOAP or MIRA assemblies adopted in previous reports $[32,33]$ were more fragmented under high values of sequencing errors 
and polymorphism levels [34]. Additionally, compared with the merged 69,480 unigenes in this transcriptome, previous studies provided relatively smaller gene sets $(29,682$ unigenes from Roche 454 system and 2139 unigenes from a SMART cDNA library) [36], and this result further emphasizes that Illumina/Hiseq-2000 RNA-Seq is a more ideal method for transcriptome analysis and it has high efficiency and massive data output.

In this study, only 60,593 unigenes were annotated with at least one database and the same problem has also been reported for the transcriptomes of other groups of marine organisms [37]. The possible reason for less annotation may be due to the availability of limited genome sequence database and research on aquaculture fish species [38-40]. Nonetheless, the functional annotations of unigenes according to GO, COG, and KEGG databases provided ample numbers of candidate genes and valuable information about biological features of koi carp challenged with $A$. sobria in this study. For example, as per the KEGG analysis, 33,057 sequences were assigned to 244 KEGG pathways, and among them, genetic information processing accounted for the largest number of pathways related to pathogen infection (Figures 2 and 3).

In the present study, identification of SSR might be useful in genetic, evolutionary, and breeding studies [41] in koi carp studies. These data on SRR will be useful in future studies on gene expression, which can be manipulated by SRR variations in the 5 UTR regions as they affect the transcription and translation. As it is evident that SRR are ubiquitous in transcriptomes and specific, this unigene could be used for molecular marker development, comparative genetic mapping and genotyping.

\section{Materials and Methods}

\subsection{Animal Maintenance}

Prior to the conduct of experiments, all the fish were kept in a recirculatory system for 2 weeks and allowed them to acclimatize to the laboratory conditions. Throughout the experiment, fish were handled with 2-phenoxyethanol as an anesthetic. Approval for animal studies was obtained from the Center for Research Animal Care and Use Committee of the National Pingtung University of Science and Technology under protocol no \#101-027 dated 19 March 2012.

\subsection{Isolation, Cultivation, and Challenge with Aeromonas Sobria}

The bacterium $A$. sobria was isolated from diseased koi carp with severe skin ulcer. The species was identified by API 20NE and 16S rDNA sequencing, cultured in brain heart infusion (BHI) broth for $18 \mathrm{~h}$ at $25^{\circ} \mathrm{C}$ and enumerated prior to the challenge test.

A total of 15 fish (body weight $325 \pm 23 \mathrm{~g}$ ) were anaesthetized and used for intraperitoneal injection with $1 \times 10^{7} \mathrm{cfu}$ per fish. Individual fish received $1 \times 10^{7} \mathrm{cfu}$ in $200 \mu \mathrm{L}$ phosphate buffered saline (PBS, pH 7.2). The other tank with 15 fish was injected with $200 \mu \mathrm{L}$ of PBS (pH 7.2) only and used as a control. Three fish each from the challenge (treatment) and control groups $(n=3)$, respectively, were examined at post $24 \mathrm{~h}$ infection. Muscle and spleen tissues were dissected hygienically and total RNA was isolated.

\subsection{Total RNA Isolation}

TRIzol ${ }^{\circledR}$ reagent (Invitrogen Corp., Carlsbad, CA, USA) was used to isolate total RNA from the tissues according to the manufacturer's instructions. RNA integrity was assessed using the RNA Nano 6000 Assay Kit on the Bioanalyzer 2100 system (Agilent Technologies, Santa Clara, CA, USA).

\section{4. cDNA Library Preparation and Sequencing}

Genomics Bioscience Technology Co. Ltd. (Taipei, Taiwan) synthesized cDNA using $40 \mu \mathrm{g}$ total RNA along with poly-T oligo-attached magnetic beads. First- and second-strand cDNA was synthesized using random oligonucleotides and SuperScript II reverse transcriptase. Illumina HiSeq ${ }^{\mathrm{TM}}$ 
2000 (Illumina, Inc., San Diego, CA, USA) platform was used to sequence the RNA-Seq library as paired-end reads to $100 \mathrm{bp}$.

\subsection{Assembly of De Novo Transcriptome}

Adaptors and unknown bases $(\mathrm{N})$ and low-quality reads were filtered using internal software and stored in FASTQ format [42]. Using the default parameter in Trinity (https://github.com/ trinityrnaseq/trinityrnaseq/wiki) assembly was performed for paired reads and clustered to unigenes via TIGR gene indices.

\subsection{Functional Unigene Annotation and Classification}

NCBI Nr (http:/ / www.ncbi.nlm.nih.gov/), the COG (http:/ / www.ncbi.nlm.nih.gov/COG/), and the KEGG (http:/ / www.genome.jp/kegg/), BlastP (Version 2.2.25) for unigenes containing open reading frames (ORFs), and BlastX for unigenes without an ORF [43] were used for annotation. The Blast2GO program was used to obtain GO annotation of the unigenes based on BLASTx hits against the NCBI Nr database [44] and aligned, and the non-aligned unigenes were predicted by ESTscan [45].

\subsection{Identification of SSRs and SNP}

SSRs were identified using MISA software package [46] (http:/ / pgrc.ipk-gatersleben.de/misa) and di-, tri-, tetra-, penta-, and hexa-nucleotide motifs with a minimum of 8, 5, 5, 5, and 5 repeats were also identified with default parameters, respectively. SNPs were identified in the unigene of koi carp using HISAT [47] (http:/ / ccb.jhu.edu/software/hisat/index.shtml), and then were called using GATK [48].

\subsection{Differentially Expressed Genes and Enrichment Analysis}

Bowtie2 software (http:/ / bowtie-bio.sourceforge.net) [49] was used to determine the expression form treatment and control library. In order to obtain the DEGs in muscle and spleen tissues between the control and the infected groups, fragments per kilobase of transcripts per million fragments mapped (FPKM) values were analyzed further using the RESM [50] and the false discovery rate (FDR) was used when it is $<0.05$.

\subsection{Real-Time Reverse Transcription Polymerase Chain Reaction}

Once the infected fish were prepared, we performed another set of experiments for the validation of RNA-Seq data. DNase I-treated total RNA from the spleen and muscle was subjected to cDNA synthesis using iScript ${ }^{\mathrm{TM}}$ cDNA synthesis kits (Bio-Rad, Hercules, CA, USA). Reverse transcriptase real-time PCR (RT-qPCR) was performed using $\mathrm{iQ}^{\mathrm{TM}} \mathrm{SYBR}^{\circledR}$ Green Supermix (Bio-Rad). The list of primer sequences is shown in Table 5. Gene expression levels were normalized to that of EF1 $\alpha$. To enable comparisons between the two groups, statistical analysis was performed using Student's $t$-test. Values of $p<0.05$ were considered statistically significant. 
Table 5. Primer name and sequence used in the present study.

\begin{tabular}{|c|c|c|}
\hline Gene & & Sequence $\left(5^{\prime}-3^{\prime}\right)$ \\
\hline \multirow{2}{*}{$E F 1 \alpha$} & Forward & 5'-CCGTTGAGATGCACCATGAGT-3' \\
\hline & Reverse & 5'-TTGACAGACACGTTCTTCACGTT-3' \\
\hline \multirow{2}{*}{$I L-1 \beta$} & Forward & 5'-GTAACGTGTGCCGGTTTCTT-3' \\
\hline & Reverse & 5'-GCAACACAAAAGGAAGCACA-3' \\
\hline \multirow{2}{*}{$T N F \alpha$} & Forward & 5'-GCTTGTAGCTGCCGTAGGAC-3' \\
\hline & Reverse & 5'-GGTGGCTTGGAATTAGTG-3' \\
\hline \multirow{2}{*}{ TLR5 } & Forward & 5'-ATACACTCCGCTGCTGCTTT-3' \\
\hline & Reverse & 5'-CAAGCTGAAGGTTTCCAAGC-3' \\
\hline \multirow{2}{*}{$I L-8$} & Forward & 5'-GATGCAAATGCCCTCAAATACA-3' \\
\hline & Reverse & 5'-GGCTCTTGACGTTCCTTTTG-3' \\
\hline \multirow{2}{*}{$N F-\kappa b$} & Forward & 5'-TGGCTGGAGAGGATCCATAC-3' \\
\hline & Reverse & 5'-AAAGCCCCTCTGTTTTGGTTG-3' \\
\hline \multirow{2}{*}{ MyD88 } & Forward & 5'-CAGTTCTGTGTTGCGACGTT-3' \\
\hline & Reverse & 5'-CGGTAAGAACTTGGCACGAT-3' \\
\hline \multirow{2}{*}{ C3 } & Forward & 5'-GGCTGGTCTTAGGCAGACAG-3' \\
\hline & Reverse & 5'-CAGCATAGGACCCGTCACTT-3' \\
\hline
\end{tabular}

\section{Conclusions}

This is the first study to provide information on host defense gene activities based on differential transcriptomic profiling in koi carp against $A$. sobria. The large number of differential expression of immune-related genes from innate immunity, antigen processing and complement cascade in this study indicated the activation of koi carp host immune response towards $A$. sorbria infection and its effect. However, further studies should be directed towards understanding of these different expressed immune genes as potential functional markers in koi carp against $A$. sobria infection. Understanding the protein levels of these functional markers in the infected koi carp would be of vital importance, as such approach may lead to a profound understanding of the regulation and responses that occur during the infection, and thus lead to the development of very specific and efficient novel vaccines and chemotherapies.

Supplementary Materials: Supplementary materials can be found at http:/ / www.mdpi.com/1422-0067/19/7/ $2107 / \mathrm{s} 1$.

Author Contributions: O.B. designed and conducted the experiments, analyzed the results, and drafted the manuscript. Y.-C.C. conducted animal management, isolation, cultivation, and challenge with A. sobria and total RNA isolation. S.M. performed q-PCR experiments and edited the manuscript. S.-C.C. and P.-C.W. monitored the experimental process and made substantial contributions toward data analysis and manuscript revision. All the authors have read and approved the final version of the manuscript.

Funding: This research was funded by National Science Council, Taiwan, grant number NSC 103-2622-B-020-004-CC1 and NSC 104-2622-B-020-002-CC1.

Acknowledgments: The authors thank Genomics Bioscience Technology Co. Ltd. (Taipei, Taiwan) for assistance with transcriptome sequencing.

Conflicts of Interest: The authors declare no conflicts of interest.

\section{References}

1. Beaz-Hidalgo, R.; Figueras, M.J. Aeromonas spp. whole genomes and virulence factors implicated in fish disease. J. Fish Dis. 2013, 36, 371-388. [CrossRef] [PubMed]

2. Figueras, M.J. Clinical relevance of Aeromonas. Rev. Med. Microbiol. 2005, 16, 145-153. [CrossRef]

3. Janda, J.M. Aeromonas and Plesiomonas. In Molecular Medical Microbiology; Sussman, M., Ed.; Academic Press: San Diego, CA, USA, 2001; pp. 1237-1270. 
4. Janda, J.M.; Abbott, S.L. The genus Aeromonas, taxonomy, pathogenicity, and infection. Clin. Microbiol. Rev. 2010, 23, 35-73. [CrossRef] [PubMed]

5. Khardori, N.; Fainstein, V. Aeromonas and Plesiomonas as etiological agents. Annu. Rev. Microbiol. 1988, 42, 395-419. [CrossRef] [PubMed]

6. Chopra, A.K.; Houston, C.W.; Peterson, J.W.; Jin, G.F. Cloning, expression, and sequence analysis of a cytolytic enterotoxin gene from Aeromonas hydrophila. Can. J. Microbiol. 1993, 39, 513-523. [CrossRef] [PubMed]

7. Nordmann, P.; Poirel, L. Emerging carbapenemases in gram-negative aerobes. Clin. Microbiol. Inf. 2002, 8, 321-331. [CrossRef]

8. Shome, R.; Shome, B.R.; Mazumder, Y.; Das, A.; Kumar, A.; Rahman, H.; Bujarbaruah, K.M. Abdominal dropsy disease in major carps of Meghalaya: Isolation and characterization of Aeromonas hydrophila. Curr. Sci. 2005, 88, 1897-1900.

9. Gram, L.; Oundo, J.O.; Bon, J. Storage life of Nile perch (Lates niloticus) in relation to temperature and initial bacterial load. Trop. Sci. 1989, 29, 221-236.

10. Popoff, M. Genus III Aeromonas. In Bergey's Manual of Systematic Bacteriology; Kluyver, A.J., Van Niel, C.J., Eds.; Williams and Wilkins: Baltimore, MD, USA, 1984; Volume 1, pp. 545-548.

11. Bernoth, E. Autoagglutination, growth on tryptonesoy-Coomassie agar, outer membrane protein patterns and virulence of Aeromonas salmonicida strain. J. Fish Microbiol. 1990, 41, 2348-2357.

12. Noga, E.J. Fish Diseases: Diagnosis and Treatment, 2nd ed.; Willey-Blackwell: Singapore, 2010.

13. Austin, B.; Austin, D.A. Bacterial Fish Pathogens: Disease in Farmed and Wild Fish; Halsted Press: New York, NY, USA, 1987.

14. Dryden, M.; Munro, R. Aeromonas septicemia: Relationship of species and clinical features. Pathology 1989, 21, 111-114. [CrossRef] [PubMed]

15. Areerat, S. Clarias culture in Thailand. Aquaculture 1987, 63, 355-362. [CrossRef]

16. Abbott, S.L.; Cheung, W.K.; Janda, J.M. The genus Aeromonas: Biochemical characteristics, atypical reactions, and phenotypic identification schemes. J. Clin. Microbiol. 2003, 41, 2348-2357. [CrossRef] [PubMed]

17. Lü, A.J.; Hu, X.C.; Wang, Y.; Zhu, A.H.; Shen, L.L.; Tian, J.; Feng, Z.Z.; Feng, Z.J. Skin immune response in the zebrafish, Danio rerio (Hamilton), to Aeromonas hydrophila infection: A transcriptional profiling approach. J. Fish Dis. 2015, 38, 137-150. [CrossRef] [PubMed]

18. Song, X.; Hu, X.; Sun, B.; Bo, Y.; Wu, K.; Xiao, L.; Gong, C. A transcriptome analysis focusing on inflammation-related genes of grass carp intestines following infection with Aeromonas hydrophila. Sci. Rep. 2017, 7, 40777. [CrossRef] [PubMed]

19. Qin, C.; Gong, Q.; Wen, Z.; Yuan, D.; Shao, T.; Wang, J.; Li, H. Transcriptome analysis of the spleen of the darkbarbel catfish Pelteobagrus vachellii in response to Aeromonas hydrophila infection. Fish Shellfish Immunol. 2017, 70, 498-506. [CrossRef] [PubMed]

20. Zhang, X.; Wang, S.; Chen, S.; Chen, Y.; Liu, Y.; Shao, C.; Wang, Q.; Lu, Y.; Gong, G.; Ding, S.; et al. Transcriptome analysis revealed changes of multiple genes involved in immunity in Cynoglossus semilaevis during Vibrio anguillarum infection. Fish Shellfish Immunol. 2015, 43, 209-218. [CrossRef] [PubMed]

21. Huang, Y.; Huang, X.; Yan, Y.; Cai, J.; Ouyang, Z.; Cui, H.; Wang, P.; Qin, Q. Transcriptome analysis of orange-spotted grouper (Epinephelus coioides) spleen in response to Singapore grouper iridiovirus. BMC Gen. 2011, 12, 556. [CrossRef] [PubMed]

22. Tran, N.T.; Gao, Z.X.; Zhao, H.H.; Yi, S.K.; Chen, B.X.; Zhao, Y.H.; Lin, L.; Liu, X.Q.; Wang, W.M. Transcriptome analysis and microsatellite discovery in the blunt snout bream (Megalobrama amblycephala) after challenge with Aeromonas hydrophila. Fish Shellfish Immunol. 2015, 45, 72-82. [CrossRef] [PubMed]

23. Cárdenas, L.; Sánchez, R.; Gomez, D.; et al. Molecular markers. Mar. Gen. 2011, 4, 197-205. [CrossRef] [PubMed]

24. Chen, J.; Li, C.; Huang, R.; Du, F.; Liao, L.; Zhu, Z.; Wang, Y. Transcriptome analysis of head kidney in grass carp and discovery of immune-related genes. BMC Vet. Res. 2012, 8, 108. [CrossRef] [PubMed]

25. Cui, J.; Wang, H.; Liu, S.; Qiu, X.; Jiang, Z.; Wang, X. Transcriptome analysis of the gill of Takifugu rubripes using Illumina sequencing for discovery of SNPs. Comp. Biochem. Physiol. Part D Genom. Proteom. 2014, 10, 44-51. [CrossRef] [PubMed] 
26. Wang, P.; Wang, J.; Su, Y.Q.; Mao, Y.; Zhang, J.S.; Wu, C.W.; Qiao-Zhen, K.; Kun-Huang, H.; Wei-Qiang, Z.; Nen-di, X. Transcriptome analysis of the Larimichthys crocea liver in response to Cryptocaryon irritans. Fish Shellfish Immunol. 2016, 48, 1-11. [CrossRef] [PubMed]

27. Zhang, R.; Zhang, L.; Ye, X.; Tian, Y.Y.; Sun, C.F.; Lu, M.X.; Bai, J.J. Transcriptome profiling and digital gene expression analysis of Nile tilapia (Oreochromis niloticus) infected by Streptococcus agalactiae. Mol. Biol. Rep. 2013, 40, 5657-5668. [CrossRef] [PubMed]

28. Zhu, J.; Li, C.; Ao, Q.; Tan, Y.; Luo, Y.; Guo, Y.; Lan, G.; Jiang, H.; Gan, X. Transcriptomic profiling revealed the signatures of acute immune response in tilapia (Oreochromis niloticus) following Streptococcus iniae challenge. Fish Shellfish Immunol. 2015, 46, 346-353. [CrossRef] [PubMed]

29. Mu, Y.; Ding, F.; Cui, P.; Ao, J.; Hu, S.; Chen, X. Transcriptome and expression profiling analysis revealed changes of multiple signaling pathways involved in immunity in the large yellow croaker during Aeromonas hydrophila infection. BMC Genom. 2010, 11, 506. [CrossRef] [PubMed]

30. Yu, S.; Mu, Y.; Ao, J.; Chen, X. Peroxiredoxin IV regulates pro-inflammatory responses in large yellow croaker (Pseudosciaena crocea) and protects against bacterial challenge. J. Proteome Res. 2010, 9, 1424-1436. [CrossRef] [PubMed]

31. Ao, J.; Mu, Y.; Xiang, L.X.; Fan, D.; Feng, M.; Zhang, S.; Shi, Q.; Zhu, L.Y.; Li, T.; Ding, Y.; et al. Genome sequencing of the perciform fish Larimichthys crocea provides insights into molecular and genetic mechanisms of stress adaptation. PLoS Genet. 2015, 11, e1005118. [CrossRef] [PubMed]

32. Kinoshita, S.; Wang, N.; Inoue, H.; Maeyama, K.; Okamoto, K.; Nagai, K.; Kondo, H.; Hirono, I.; Asakawa, S.; Watabe, S. Deep sequencing of ESTs from nacreous and prismatic layer producing tissues and a screen for novel shell formation-related genes in the pearl oyster. PLoS ONE 2011, 6, e21238. [CrossRef] [PubMed]

33. Zhao, X.; Wang, Q.; Jiao, Y.; Huang, R.; Deng, Y.; Wang, H.; Du, X. Identification of genes potentially related to biomineralization and immunity by transcriptome analysis of pearl sac in pearl oyster Pinctada martensii. Mar. Biotechnol. 2012, 14, 730-739. [CrossRef] [PubMed]

34. Zhao, Q.Y.; Wang, Y.; Kong, Y.M.; Luo, D.; Li, X.; Hao, P. Optimizing de novo transcriptome assembly from short-read RNA-Seq data: A comparative study. BMC Bioinf. 2011, 12, S2. [CrossRef] [PubMed]

35. Vijay, N.; Poelstra, J.W.; Künstner, A.; Wolf, J.B.W. Challenges and strategies in transcriptome assembly and differential gene expression quantification. A comprehensive in silico assessment of RNA-seq experiments. Mol. Ecol. 2013, 22, 620-634. [CrossRef] [PubMed]

36. Wang, A.; Wang, Y.; Gu, Z.; Li, S.; Shi, Y.; Guo, X. Development of expressed sequence tags from the pearl oyster, Pinctada martensii dunker. Mar. Biotechnol. 2011, 13, 275-283. [CrossRef] [PubMed]

37. Meyer, E.; Aglyamova, G.V.; Wang, S.; Buchanan-Carter, J.; Abrego, D.; Colbourne, J.K.; Willis, B.L.; Matz, M.V. Sequencing and de novo analysis of a coral larval transcriptome using 454 GSFlx. BMC Genom. 2009, 10, 219. [CrossRef] [PubMed]

38. Chu, S.L.; Weng, C.F.; Hsiao, C.D.; Hwang, P.P.; Chen, Y.C.; Ho, J.M.; Lee, S.J. Profile analysis of expressed sequence tags derived from the ovary of tilapia, Oreochromis mossambicus. Aquaculture 2006, 251, 537-548. [CrossRef]

39. Dong, B.; Xiang, J.H. Discovery of genes involved in defense/immunity functions in a haemocytes cDNA library from Fenneropenaeus chinensis by ESTs annotation. Aquaculture 2007, 272, 208-215. [CrossRef]

40. Novaes, E.; Drost, D.R.; Farmerie, W.G.; Pappas, G.J.; Grattapaglia, D.; Sederoff, R.R.; Kirst, M. High-throughput gene and SNP discovery in Eucalyptus grandis, an uncharacterized genome. BMC Genom. 2008, 9, 312. [CrossRef] [PubMed]

41. Li, Y.C.; Korol, A.B.; Fahima, T.; Nevo, E. Microsatellites within genes: structure, function, and evolution. Mol. Biol. Evol. 2004, 21, 991-1007. [CrossRef] [PubMed]

42. Cock, P.J.; Fields, C.J.; Goto, N.; Heuer, M.L.; Rice, P.M. The Sanger FASTQ file format for sequences with quality scores, and the Solexa/Illumina FASTQ variants. Nucleic Acids Res. 2010, 38, 1767-1771. [CrossRef] [PubMed]

43. Camacho, C.; Coulouris, G.; Avagyan, V.; Ma, N.; Papadopoulos, J.; Bealer, K.; Madden, T.L. BLAST+: architecture and applications. BMC Bioinf. 2009, 10, 421. [CrossRef] [PubMed]

44. Conesa, A.; Geotz, S.; García-Gomez, J.M.; Terol, J.; Talon, M.; Robles, M. Blast 2 GO a universal tool for annotation, visualization and analysis in functional genomics research. Bioinformatics 2005, 21, 3674-3676. [CrossRef] [PubMed] 
45. Iseli, C.; Jongeneel, C.V.; Bucher, P. ESTScan: A program for detecting, evaluating, and reconstructing potential coding regions in EST sequences. Proc. Int. Conf. Intell. Syst. Mol. Biol. 1999, 99, 138-148.

46. Thiel, T.; Michalek, W.; Varshney, R.; Graner, A. Exploiting EST databases for the development and characterization of gene-derived SSR-markers in barley (Hordeum vulgare L.). Theor. Appl. Genet. 2003, 106, 411-422. [CrossRef] [PubMed]

47. Kim, D.; Langmead, B.; Salzberg, S.L. HISAT: A fast spliced aligner with low memory requirements. Nat. Met. 2015. [CrossRef] [PubMed]

48. McKenna, A.; Hanna, M.; Banks, E.; Sivachenko, A.; Cibulskis, K.; Kernytsky, A.; Garimella, K.; Altshuler, D.; Gabriel, S.; Daly, M.; et al. The Genome Analysis Toolkit: A MapReduce framework for analyzing next-generation DNA sequencing data. Genome Res. 2010, 20, 1297-1303. [CrossRef] [PubMed]

49. Langmead, B.; Salzberg, S.L. Fast gapped-read alignment with Bowtie 2. Nat. Met. 2012, 9, 357-359. [CrossRef] [PubMed]

50. Li, B.; Dewey, C.N. RSEM: Accurate transcript quantification from RNA-Seq data with or without a reference genome. BMC Bioinf. 2011, 12, 323. [CrossRef] [PubMed]

(C) 2018 by the authors. Licensee MDPI, Basel, Switzerland. This article is an open access article distributed under the terms and conditions of the Creative Commons Attribution (CC BY) license (http:/ / creativecommons.org/licenses/by/4.0/). 